\title{
Health leaders must share the reins of reform: outgoing CMA pres
}

\author{
n Cite as: CMAJ 2017 September 11;189:E1170. doi: 10.1503/cmaj.1095487
}

Posted on cmajnews.com on Aug. 22, 2017.

anada's health leaders missed "golden opportunities" for health reform in the past year, and physicians are paying the price, said Dr. Granger Avery in his valedictory address to the Canadian Medical Association.

From "so-called discussions" about building a new health accord, to the federal budget, to this summer's meeting of Canada's premiers, "at each opportunity, governments dropped the ball," he said. "Worse yet, where were Canadians as these golden opportunities slipped by? Where were our Aboriginal and First Nations peoples? Regrettably absent."

Canada's health system and medical profession are at a crossroads, Avery said. At a time when patient expectations and demands are increasing, doctors are beset with tougher regulatory requirements, substantial income reductions, and "pernicious and denigrating" attacks on their profession by governments. These pressures contribute to "disastrous levels of burnout and depression existing in our profession, starting even among our students," he said.

In his travels across the country, Avery heard from "many, many of our own colleagues that they had lost the joy in medicine." In one area, "over half of physicians identified as being burnt out."

"To hear these feelings of powerlessness, of desperation, expressed by colleagues is gut wrenching," Avery said. But even in the face of these challenges, he urged doctors not to lose sight of what unites them with their patients and with each other.

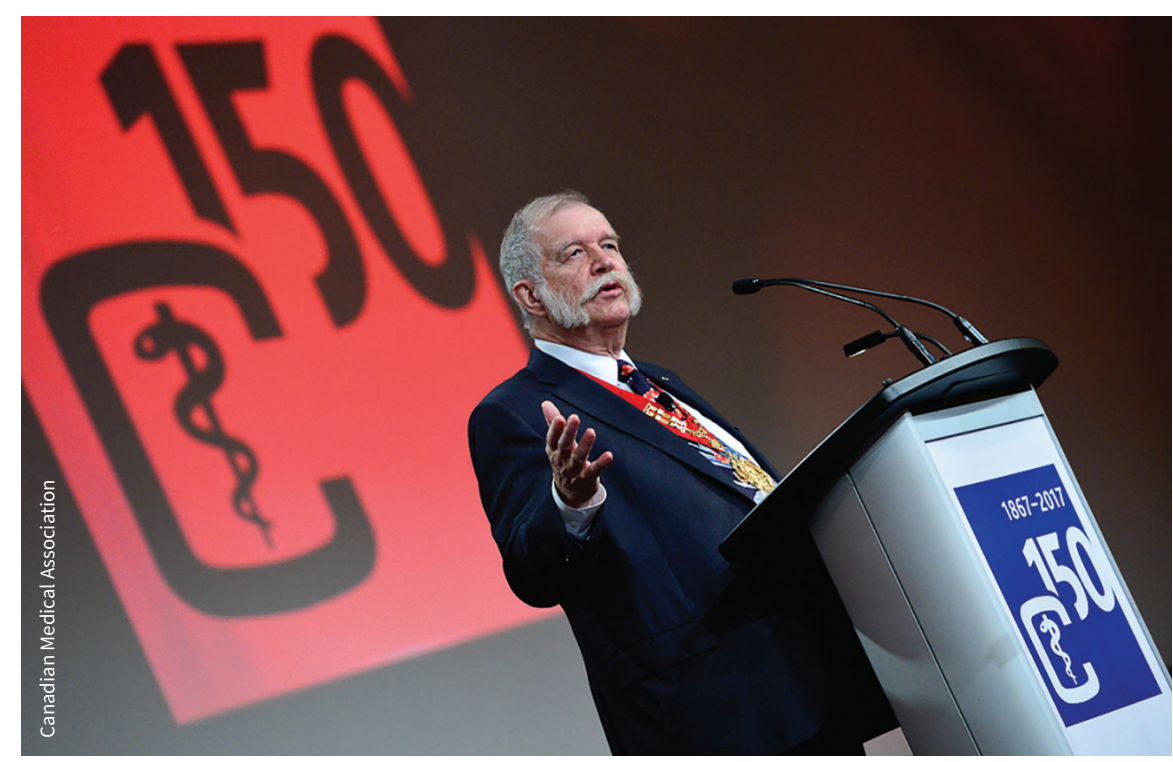

Governments' "command and control" approach to health reform isn't working, said Canadian Medical outgoing president Dr. Granger Avery.

"The key to moving forward is to unite around our shared commitment to each other and our dedication to maintaining a strong patient-physician relationship, while providing excellent medical scientific advice," Avery said. "This is the bedrock foundation of medical professionalism."

He also called on governments to engage in "truly collaborative health care decision-making with all the partners in health."

"We cannot expect to make effective, sustainable decisions about health care organization and delivery without the involvement, commitment and accountability of the people who fund, deliver and receive these services," Avery explained. "Time and again, we see our current command and control model of health system governance failing us all miserably."

He acknowledged that given "how far our system has spiraled down," calling for collaboration "is difficult for many people to accept."

However, Avery argued that the current adversarial climate simply proves the need for a collaborative approach even more. "We have spent 50 years doing it the other way and where are we? If we want improvement, we really don't have any other choice."

\section{Lauren Vogel, CMAJ}

